\title{
Study on the Uncertainty of Absolute Measurement of LED Luminous Flux
}

\author{
Qiyu $\mathrm{Lu}^{1}$, Guliang $\mathrm{Zhou}^{2}$, Yuansheng $\mathrm{Dai}^{2}$, Chenzhao $\mathrm{Fu}^{2}$ and $\mathrm{Kan} \mathrm{Xu}^{1}$ \\ ${ }^{1}$ State Grid Electric Power Research Institute of Shanghai Electric Power Corporation, Shanghai, 200437, China; \\ ${ }^{2}$ State Grid Shanghai Electric Power Corporation, Shanghai, 200122, China
}

\begin{abstract}
Distributed photometer for measuring light flux is a relatively accurate method, but for different beam angles and different test conditions, it can also bring errors. In this paper, we use the distribution of photometric method to measure luminous flux for different beam angle of the LED under different parameters. By analyzing the experimental data and combining with the light distribution curve, the uncertain factors and their effects in the measurement of LED luminous flux,absolute method are summarized, and the experimental parameters are optimized for different beam angle LED.
\end{abstract} angle

Keywords- LED; luminous flux; distributed photometer; beam

\section{INTRODUCTION}

The luminous flux is an important parameter in characterizing the characteristics of the light source, and has been widely used in the electric light source industry and lighting engineering. The luminous flux of the light source can be measured by means of a distributed photometer or integrating sphere $[1,2]$. Although the integral ball method is simple and the equipment is less, the self-absorption effect of the objects in the sphere is integrated, which makes the integrating sphere deviate from the ideal integrating sphere which leads to the test principle error and the measurement accuracy is not high. Especially for the LED light source, due to its small size, narrow beam and other characteristics, the use of integrating sphere measurement of its luminous flux will cause a greater error, or even $30 \%-40 \%$; while the integration of the ball method for the relative measurement method is done, we must use the luminous flux standard lamp and the system is calibrated [3]. The distribution of luminous flux is measured by measuring the spatial light intensity distribution curve of the light source and calculating the luminous flux of the light source by integrating. Distribution photometer is an absolute measurement method, is a more accurate method. Measuring the luminous flux with a distributed photometer does not require a standard lamp, but also can be calculated according to the intensity distribution of regional luminous flux, light efficiency, beam angle and so on. The light source and lamps are very important parameters.

Although the distribution of photometer measurement of light source luminous flux in principle is absolutely accurate method, but in the actual measurement process, due to instrument measurement accuracy, measurement conditions, measurement parameters, it will also cause a larger measurement error. Especially for the new light source LED, its size, type, color, beam angle and other types, for different colors, different beam angle LED with the same instrument to measure its luminous flux, it will bring different measurement error. For the same LED, when using different experimental parameters, it will cause the measurement results of the error.

In this paper, LED samples with different beam angles, different colors and different powers are tested and analyzed. The uncertainty factors and the errors caused by the luminous flux are analyzed by a distributed photometer. In different light beam angles and different colors of LEDs, the comparison was made to propose a more accurate and time-saving measurement of LED luminous flux for optimal parameter setting.

\section{PRINCIPLE AND Method OF ABSOlUte Method FOR MEASURING LED LUMINOUS FLUX}

The distribution photometer is an absolute method for measuring the luminous flux of the light source. Its basic function is to measure the spatial distribution of the luminous intensity of the light source, and the luminous flux of the light source to the space is calculated by the integral calculation.

According to the law of distance square inverse, the formula for expressing the relationship between illuminance and light intensity is:

$$
E=\frac{I \cdot \operatorname{Cos} \theta}{r^{2}}
$$

Where $\mathrm{E}$ is the illuminance on the light receiving surface, I is the light intensity, $\mathrm{r}$ is the distance from the light source to the light receiving surface, and $\theta$ is the angle between the center of the beam and the normal of the light receiving surface. In this experimental instrument, $\theta$ is always 0 , so $\operatorname{Cos} \theta$ is always 1 [4], the formula is simplified as:

$$
E=\frac{I}{r^{2}}
$$

$$
I=E \bullet r^{2}
$$

The luminous flux is calculated as follows:

For axisymmetric light sources, there are: 


$$
\Phi=2 \pi \int_{0}^{\pi} I_{i} \sin \theta d \theta=\int I_{i} d \Omega_{i}
$$

In the formula, the measured light intensity on each micro-face is the solid angle of the corresponding microelement [5].

Distribution photometer measurement principle is shown in Figure 1 and the measured LED light source is in a virtual spherical sphere. The ball with the corresponding light intensity will be closed into a lot of spherical sphere and the area of the ball. By measuring the illuminance values of the tiny facets on the spherical surface with radius $r$, the light intensity and the solid angle corresponding to the micro-facets are calculated to achieve the luminous flux measurement.

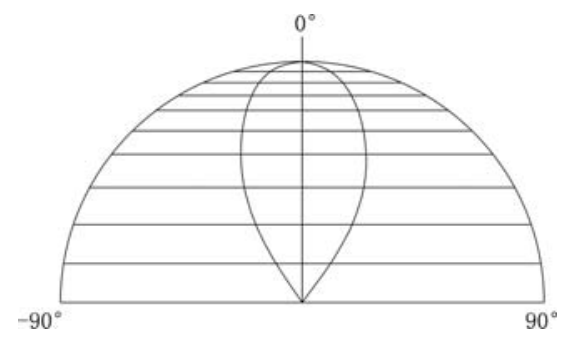

FIGURE I. THE DIVISION OF THE BELT

For the LED light source measurement of the use of precision small distributed photometer, in the dark room to measure, we should ensure that the measurement process from external light interference. Special LED distribution photometer generally has two structures [6]: one is LED fixed, photometric probe around it rotation scan; the other is the photometric probe is not fixed, LED around the top of the package shell for rotation scan. For conventional light sources such as incandescent lamps, in order to avoid the filament in the bubble due to rotation and shaking, we must use the former measurement; and for the LED such solid light source, the two methods can be used. The small distributed photometer used in this paper is used in the second way, by turning the vertical axis of the LED and the probe remains fixed to achieve the measurement. As the vertical axis through the LED light center, it is equivalent to the probe around the LED in a certain distance from the LED on the spherical surface for circular motion.

Luminous intensity of the spatial distribution curve (light distribution curve) is made for incandescent, fluorescent, etc. Its distribution is almost close to $4 \pi$ space. But for the LED, because of its strong direction, the general light angle is less than 180 degrees, so in this test we take \pm 90 degrees.

\section{EXPERIMENTAL TESTING AND ANALYSIS}

This article uses LED dedicated distribution photometer LED626 LED luminous flux measurement. The distribution of the photometer using the coordinate system, because the coordinate system can be eye-catching understanding of the LED in the space of all light distribution curve, and is easy to calculate. CIE Publication No.127-1997 specifies two standard measurement conditions for LEDs, namely measuring conditions A and B. In this paper, CIE A condition $(316 \mathrm{~mm}$, far field) is used. Measured LED light source selection $1 \mathrm{~W}$, $0.06 \mathrm{~W}$ a total of four models of LED, the specific classification is shown in Table I.

TABLE I. TEST LED CLASSIFICATION TABLE

\begin{tabular}{llll}
\hline number & $\begin{array}{l}\text { Light } \\
\text { color }\end{array}$ & shape & power \\
\hline 1 & white & High power package & $1 \mathrm{~W}$ \\
2 & white & Straw hat type & $0.06 \mathrm{~W}$ \\
3 & blue & High power package & $1 \mathrm{~W}$ \\
4 & blue & Straw hat type & $0.06 \mathrm{~W}$ \\
\hline
\end{tabular}

A. The Test Results of Different Sampling Intervals

$\gamma$ is the sampling interval angle, the sampling angle range is between $\pm 90^{\circ}$, the adjustable angle interval $\gamma$ is $0.5^{\circ}, 1^{\circ}, 2^{\circ}$, $5^{\circ} ; \mathrm{C}$ is the rotation interval angle, the smaller the angle the more plane, the longer the test time, Adjustable angle interval $\mathrm{C}$ is $5^{\circ}, 10^{\circ}, 15^{\circ}, 30^{\circ}, 45^{\circ}$.

First, this paper examines the effects of different gammaangle intervals on different types of LED test results when determining the luminous flux of LEDs in absolute law. Using the control variable method, the rotation interval $\mathrm{C}$ fixed at $5^{\circ}$, $\gamma$ angle in turn $0.5^{\circ}, 1^{\circ}, 2^{\circ}, 5^{\circ}$. For high-power LED, the use of constant current $350 \mathrm{~mA}$, the test in order to eliminate the impact of temperature on the test results, this paper will be lit after the LED light for 30 minutes to achieve thermal balance and then test; for low-power LED, constant current 20mA. The test results are shown in Table II to Table V. The calculation of the relative error of the luminous flux in the table is based on the measurement of $0.5^{\circ}$ at the angle $\gamma$.

TABLE II. LOMBARD BODY LIGHT HIGH-POWER WHITE LED TEST RESULTS

\begin{tabular}{lllll}
\hline $\mathrm{C}$ & $\gamma$ & $\begin{array}{l}\text { Average } \\
\text { angle } \theta_{a v} 50 \%\end{array}$ & $\begin{array}{l}\text { Luminous } \\
\text { flux }\end{array}$ & $\begin{array}{l}\text { Luminous flux } \\
\text { relative error }\end{array}$ \\
\hline 5 & 0.5 & 106.8 & 70.26 & \\
5 & 1 & 106.3 & 69.94 & $-0.455 \%$ \\
5 & 2 & 106,7 & 70.64 & $0.541 \%$ \\
5 & 5 & 106.3 & 70.68 & $0.598 \%$ \\
\hline
\end{tabular}

TABLE III. NARROW BEAM LIGHT DISTRIBUTION LOW POWER WHITE LED TEST RESULTS

\begin{tabular}{ccccc}
\hline $\mathrm{C}$ & $\gamma$ & $\begin{array}{c}\text { Average beam } \\
\text { angle } \theta_{a v} 50 \%\end{array}$ & $\begin{array}{c}\text { Luminous } \\
\text { flux }\end{array}$ & $\begin{array}{c}\text { Luminous } \\
\text { flux relative } \\
\text { error }\end{array}$ \\
\hline 5 & 0.5 & 16.8 & 1.315 & \\
5 & 1 & 16.8 & 1.291 & $-1.825 \%$ \\
5 & 2 & 16.8 & 1.325 & $0.760 \%$ \\
5 & 5 & 16.8 & 1.340 & $1.901 \%$ \\
\hline
\end{tabular}


TABLE IV. LAMBERTIAN BODY WITH HIGH POWER BLUE LED TEST RESULTS

\begin{tabular}{lllll}
\hline $\mathrm{C}$ & $\gamma$ & $\begin{array}{l}\text { Average beam } \\
\text { angle } \theta_{a v} 50 \%\end{array}$ & $\begin{array}{l}\text { Luminous } \\
\text { flux }\end{array}$ & $\begin{array}{l}\text { Luminous } \\
\text { flux } \\
\text { relative } \\
\text { error }\end{array}$ \\
\hline 5 & 0.5 & 135.8 & 11.95 & \\
5 & 1 & 135.8 & 11.94 & $-0.0834 \%$ \\
5 & 2 & 135.9 & 11.93 & $-0.167 \%$ \\
5 & 5 & 135.8 & 11.91 & $-0.335 \%$ \\
\hline
\end{tabular}

TABLE V. NARROW BEAM LIGHT DISTRIBUTION LOW POWER BLUE LED TEST RESULTS

\begin{tabular}{lllll}
\hline $\mathrm{C}$ & $\gamma$ & $\begin{array}{l}\text { Average beam } \\
\text { angle } \theta_{a v} 50 \%\end{array}$ & $\begin{array}{l}\text { Luminous } \\
\text { flux }\end{array}$ & $\begin{array}{l}\text { Luminous } \\
\text { flux } \\
\text { relative } \\
\text { error }\end{array}$ \\
\hline 5 & 0.5 & 28.3 & 0.2706 & \\
5 & 1 & 28.4 & 0.2733 & $0.998 \%$ \\
5 & 2 & 28.5 & 0.2743 & $1.367 \%$ \\
5 & 5 & 28.9 & 0.2802 & $3.548 \%$ \\
\hline
\end{tabular}

It can be seen from Table III and Table V that for LEDs with narrow beams, such as the No. 2 and No. 4 LEDs in this paper, there is a large error in the measurement of the luminous flux when the sampling interval $\gamma$ angle changes. The reason is that when the $\gamma$ angle increases, in a plane within the photometric probe sampling points decreased, combined with narrow beam LED light distribution curve in the small angle of the rapid changes in the characteristics of the resulting luminous flux relative error. Therefore, when measuring the luminous flux of a narrow beam LED, if a higher measurement accuracy is required, the sampling interval of the gamma angle should be reduced, and the minimum interval of 0.5 degrees used in this paper can be chosen, which will make the test data more accurate.

From Table II and Table IV, the Lambertian Body Light LED has a wide average beam angle of 100 degrees or more. As in the experiment, No. 1 and No. 3 LEDs, the luminous flux relative measurement error are within $0.6 \%$. To achieve a higher accuracy, therefore, in measuring the beam angle of a wide LED, you can increase the gamma angle interval, which can save the test time, while ensuring a certain degree of accuracy.

\section{B. The Angle C Takes the Measurement Result at Different Intervals}

Using the control variable method, the $\gamma$ angle is fixed at $5^{\circ}$, and the rotation interval $\mathrm{C}$ is sequentially changed by $5^{\circ}, 10^{\circ}$, $15^{\circ}, 30^{\circ}$ and $45^{\circ}$. The test results are shown in Table VI to Table I.

TABLE VI. LAMBERTIAN BODY WITH HIGH POWER WHITE LED TEST RESULTS

\begin{tabular}{lllll}
\hline $\mathrm{C}$ & $\gamma$ & $\begin{array}{l}\text { Average } \\
\text { beam angle } \\
\theta_{a v} 50 \%\end{array}$ & $\begin{array}{l}\text { Luminou } \\
\text { s flux }\end{array}$ & $\begin{array}{l}\text { Luminous } \\
\text { flux } \\
\text { relative } \\
\text { error }\end{array}$ \\
\hline 5 & 5 & 106.3 & 71.03 & \\
\hline
\end{tabular}

\begin{tabular}{lllll}
\hline 10 & 5 & 106.3 & 70.95 & $-0.113 \%$ \\
15 & 5 & 106.3 & 70.86 & $-0.239 \%$ \\
30 & 5 & 106.4 & 70.69 & $-0.479 \%$ \\
45 & 5 & 106.3 & 70.63 & $-0.563 \%$ \\
\hline
\end{tabular}

TABLE VII. NARROW BEAM LIGHT DISTRIBUTION LOW POWER WHITE LED TEST RESULTS

\begin{tabular}{lllll}
\hline $\mathrm{C}$ & $\gamma$ & $\begin{array}{l}\text { Average } \\
\text { beam } \\
\theta_{a v} 50 \%\end{array}$ & $\begin{array}{l}\text { Luminous } \\
\text { flux }\end{array}$ & $\begin{array}{l}\text { Luminous } \\
\text { flux } \\
\text { relative } \\
\text { error }\end{array}$ \\
\hline 5 & 5 & 22.5 & 1.343 & \\
10 & 5 & 22.4 & 1.335 & $-0.596 \%$ \\
15 & 5 & 22.6 & 1.329 & $-1.042 \%$ \\
30 & 5 & 22.3 & 1.319 & $-1.787 \%$ \\
45 & 5 & 22.4 & 1.303 & $-2.978 \%$ \\
\hline
\end{tabular}

TABLE VIII. LAMBERTIAN BODY WITH HIGH POWER BLUE LED TEST RESULTS

\begin{tabular}{lllll}
\hline $\mathrm{C}$ & $\gamma$ & $\begin{array}{l}\text { Average beam } \\
\text { angle } \theta_{a v} 50 \%\end{array}$ & $\begin{array}{l}\text { Luminous } \\
\text { flux }\end{array}$ & $\begin{array}{l}\text { Luminous } \\
\text { flux } \\
\text { relative } \\
\text { error }\end{array}$ \\
\hline 5 & 5 & 135.8 & 11.70 & \\
10 & 5 & 135.8 & $1 \mathrm{i}, 75$ & $0.427 \%$ \\
15 & 5 & 135.9 & 11.75 & $0.427 \%$ \\
30 & 5 & 136.1 & 11.79 & $0.769 \%$ \\
\hline 45 & 5 & 136.0 & 11.77 & $0.598 \%$ \\
\hline
\end{tabular}

TABLE IX. NARROW BEAM LIGHT DISTRIBUTION LOW POWER BLUE LED TEST RESULTS

\begin{tabular}{lllll}
\hline C & $\gamma$ & $\begin{array}{l}\text { Average beam } \\
\text { angle } \theta_{a v} 50 \%\end{array}$ & $\begin{array}{l}\text { Luminous } \\
\text { flux }\end{array}$ & $\begin{array}{l}\text { Luminous } \\
\text { flux } \\
\text { relative } \\
\text { error }\end{array}$ \\
\hline 5 & 5 & 28.9 & 0.2802 & \\
10 & 5 & 29.0 & 0.2809 & $0.249 \%$ \\
15 & 5 & 29.0 & 0.2809 & $0.249 \%$ \\
30 & 5 & 28.9 & 0.2805 & $0.107 \%$ \\
45 & 5 & 29.2 & 0.2798 & $0.143 \%$ \\
\hline
\end{tabular}

The experimental results show that the relative error of luminous flux measurement is within $0.8 \%$ for LED 1,3 and 4 , and the relative error of luminous flux test is large for LED No. 2 , which is due to asymmetry of light distribution curve, And the coincidence is poor, as shown in Figure II (b). Figure II (a) - (d) are the experimental results of 1 to 4 LED light distribution curve and each figure in different colors of the curve.The different values in $\mathrm{C}$ that is corresponding to different plane light distribution curve. For the 1,3,4 LED, the plane light distribution curve of the degree of symmetry and symmetry are better, so when the $\mathrm{C}$ value changes, that is, change the number of measurements taken by the plane, the luminous flux test results have little effect. Therefore, in the actual measurement, the $\mathrm{C}$ value can be increased, thus greatly reducing the time required for testing. For the actual measurement, it is very meaningful. 


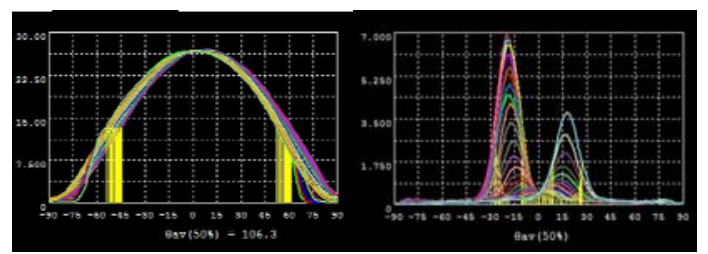

(a)

(b)

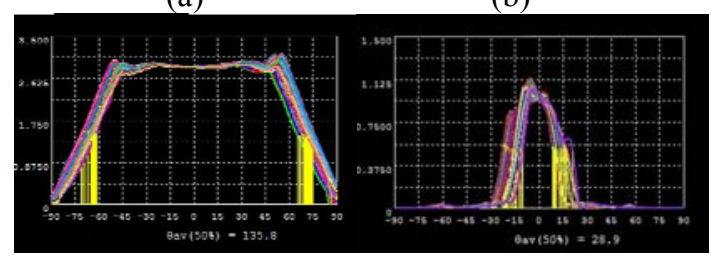

(c)

(d)

[3] Liu Muqing, Zhou Xiaoli, Li Wenyi et al. Study on methodology of LED's luminous flux measurement with integating sphere. Journal of Physics D: Applied.Physics, 2008, 41144012.

[4] EVERFINE PHOTO-E-INFO CO.LTD, LED626 LED

[5] Zhou Taiming, light source principle and design, Fudan University Press, December 2006 second edition.

[6] Lu Zheng, etc., from the LED light distribution curve, China Lighting, 2004 tenth issue.

In the experiment, in order to accurately measure the data, we need to pay attention to the following:

(1) The ambient temperature at the time of measurement. The light output of the LED decreases with increasing temperature. This not only refers to its relative spectral power distribution, but also the total radiated power emitted, and it will vary with temperature. Therefore, the ambient temperature is set at $25 \pm 0.2 \mathrm{C}$.

(2) For high-power LEDs, warm-up is required after lighting and before testing. In this experiment, the warm-up time was set to $30 \mathrm{~min}$.

(3) In the LED installation process, we should try to ensure that the LED optical center placed on the optical axis, in the experiment can be installed by a LED after the implementation of a control variable experiment, you can avoid the error caused by manual operation.

\section{CONCLUSION}

In this paper, the luminous flux measurement of the LED with different beam angle is carried out by the distributed photometer method. For the narrow beam angle LED, the sampling interval $\gamma$ angle is the main factor that affects the uncertainty of the luminous flux measurement, and for each plane light distribution curve coincidence degree and symmetry, the poor angle of the $\mathrm{C}$, which determines the number of sampling planes, is the main factor that affects the uncertainty of the luminous flux measurement. Depending on the type of LED, optimizing the measurement parameters during the test will not only benefit measurement accuracy, but also save a lot of test time.

\section{REFERENCES}

[1] Kathleen Muray. New International Recommendations on LED Measurements. Proceedings of SPIE, 1997, Vol.3140:12-18J. Clerk Maxwell, A Treatise on Electricity and Magnetism, 3rd ed., vol. 2. Oxford: Clarendon, 1892, pp.68-73.

[2] Donghui Wang,Hui Qian, Xin yuan. Fast and high-accuracy spectral measurements of LED by linear CCD sensor and software calibration. Proceedings of SPIE, 2005,Vol.5633:578-584K. Elissa, "Title of paper if known," unpublished. 